\title{
Powerful partnership: crosstalk between pannexin 1 and the cytoskeleton
}

\author{
Andrew K. J. Boyce ${ }^{1+}$, Leigh E. Wicki-Stordeur ${ }^{1+}$ and Leigh Anne Swayne ${ }^{1,2,3,4 *}$ \\ ' Division of Medical Sciences, University of Victoria, Victoria, BC, Canada \\ ${ }^{2}$ Department of Biology, University of Victoria, Victoria, BC, Canada \\ ${ }^{3}$ Department of Biochemistry and Microbiology, University of Victoria, Victoria, BC, Canada \\ ${ }^{4}$ Department of Cellular and Physiological Sciences and Island Medical Program, University of British Columbia, Vancouver, BC, Canada
}

\section{Edited by:}

Georg Zoidl, York University, Canada

Reviewed by:

Ritva Tikkanen, Justus-Liebig

University of Giessen, Germany

Georg Zoidl, York University, Canada

*Correspondence:

Leigh Anne Swayne, Division of

Medical Sciences, University of

Victoria, 3800 Finnerty Road,

Victoria, BC V8P 5C2, Canada

e-mail: Iswayne@uvic.ca

${ }^{\dagger}$ These authors have contributed equally to this work.
The roles of pannexin 1 (Panx1) large-pore ion and metabolite channels are becoming recognized in many physiological and pathophysiological scenarios. Recent evidence has tightly linked Panx1 trafficking and function to the cytoskeleton, a multi-component network that provides critical structural support, transportation, and scaffolding functions in all cell types. Here we review early work demonstrating the mechanosensitive activation of Panx 1 channels, and expand on more recent evidence directly linking Panx 1 to the cytoskeleton. Further, we examine the reciprocal regulation between Panx1 and the cytoskeleton, and discuss the involvement of Panx 1 in cytoskeletal-regulated cell behaviors. Finally, we identify important gaps in the current knowledge surrounding this emerging Panx1-cytoskeleton relationship.

Keywords: pannexin, Panx1, cytoskeleton, actin, mechanosensitive channels, mechanotransduction

\section{INTRODUCTION}

Mechanical forces shape virtually all biological processes in myriad ways (for a recent review see Lim et al., 2010). The cytoskeleton is a complex interconnected protein meshwork that plays a critical role in cellular biomechanics. Its many components and accessory/regulatory proteins provide structural stability and shape, conduits for the transport of vesicles and macromolecules, and scaffolding for receptors and ion channels. It also communicates with multiple signaling pathways within and outside of cells to modulate these activities in response to the ever-changing demands of cells and their environments (Jaqaman and Grinstein, 2012). Mechanosensitive channels provide an important means of crosstalk between chemical and mechanical signaling systems. These are channels that pass molecules and/or ions in response to stretch, and are often intimately associated with the cytoskeleton (reviewed in Hamill, 2006).

The pannexins (Panxs) were initially discovered as homologs to the innexin invertebrate gap junction protein family (Panchin et al., 2000). The initial electrophysiological characterization of Panxl channels provided evidence of a large conductance activated by membrane depolarization (Bruzzone et al., 2003). Soon after this ground-breaking finding, Bao et al. (2004) made a further striking discovery. They uncovered an activation mechanism relating the activation of Panx1 to mechanical deformation, and they provided the first demonstration that Panxl can form single membrane mechanosensitive channels. They also provided the first evidence for the role of Panxl in adenosine triphosphate (ATP) release, which is perhaps one of the most well-known features of these large pore channels.

These expression system findings have since been expanded to erythrocytes (Locovei et al., 2006), lung epithelium (SeminarioVidal et al., 2011; Richter et al., 2014), and more recently, neurons
(Xia et al., 2012). Further, Panx1 has been shown to physically interact with the actin cytoskeleton (Bhalla-Gehi et al., 2010; Wicki-Stordeur and Swayne, 2013) and the expression of Panx1 exhibits a significant level of control over multiple cytoskeletal elements (Penuela et al., 2012). Here we discuss these findings and identify key knowledge gaps that will be important to further unravel the potentially powerful relationship between Panx 1 and the cytoskeleton.

\section{ACTIVATION OF Panx1 BY MECHANICAL STRESS}

The first demonstration of stretch-mediated Panx1 opening resulted from work in an ectopic expression system by Bao et al. (2004). The authors investigated whether Panxl exhibits the properties of a mechanical conduit for ATP by expressing human Panx1 in Xenopus oocytes. In cell-free and cell-attached membrane patches, they observed a large conductance attributed to Panx1 expression that exhibited depolarization-dependent activation associated with ATP release. To test for mechanosensitive properties, they used single channel patch clamp coupled with a negative pressure stimulus (via suction applied to the patch pipette). This mechanical stimulation superseded voltage dependent activation, as it occurred over a wide range of membrane potentials.

A network of actin, known as the cellular "cortex," forms a tight association with the plasma membrane acting as molecular scaffold for ion channels and receptors (recently reviewed in Salbreux et al., 2012). While it is sometimes assumed that the cytoskeleton is not present in excised membrane patches in electrophysiological experiments, it is in fact normally present unless specific measures are taken to disrupt the tight cytoskeleton/membrane association (recently reviewed in Hamill, 2006). For example, amongst several groups investigating this intriguing 
question, by elegantly combining scanning force microscopy with patch-clamping techniques, Sakmann's lab (Horber et al., 1995) confirmed the continued presence of the cytoskeleton in cell-free membrane patches. Further, a recent elegant study has demonstrated that the actin cytoskeleton functions as a "molecular device" in the activation of mechanosensitive channels by both concentrating and conducting the forces required for channel opening (Hayakawa et al., 2008). Although this has not yet been directly tested in the context of Panxl channels, it is certainly of interest in light of the recent discovery of the Panx1 physical association with actin (Bhalla-Gehi et al., 2010; Wicki-Stordeur and Swayne, 2013).

Although quite unlike one another in many ways, erythrocytes, lung epithelium, and neurons are all linked by their responsiveness to mechanical deformation through Panx1-mediated ATP release. Locovei et al. (2006) observed that Panxl is present in human erythrocytes, and mediates ATP release and ion flux in response to depolarization and mechanical stretch elicited by pressure in the patch pipette. Another group (Seminario-Vidal et al., 2011) later revealed the role of Panx1 as the ATP conduit responsive to bronchial and tracheal epithelial cell swelling (via hypotonic challenge). Interestingly, their data pointed to a mechanism by which RhoA, a regulator of the actin cytoskeleton in the formation of stress fibers, transduces cell swelling to Panx1 opening. Recently, Richter and colleagues confirmed the role of Panx1 in ATP release from lung epithelial cells in response to stretch. In this case ATP release via Panxl was elicited by changes in hydrostatic pressure (Richter et al., 2014). An intriguing downstream effect of the hydrostatic pressure-induced ATP release from cells was a concomitant activation of $\mathrm{K}_{A T P}$ channels. It will be interesting to see whether this functional relationship is relevant to other cell types in which Panxl and $\mathrm{K}_{\text {ATP }}$ channels are co-expressed. More recently, another group (Xia et al., 2012) confirmed the involvement of Panx1 in mechanical deformation-mediated ATP release of retinal ganglion neurons using both a hypotonic solution paradigm and a special cell-stretching chamber.

While mechanical stretch-mediated ATP release can be a physiological phenomenon for erythrocytes and airway epithelia, it is normally associated with pathophysiology in the context of the nervous system. Here, mechanical stretch via impact-mediated axonal deformation or secondary to swelling is associated with neuronal injury (recently reviewed in Laplaca and Prado, 2010). We recently showed, however, that nervous system resident neural stem and progenitor cells, migrating neuroblasts and newborn neurons also express Panx1 (Wicki-Stordeur et al., 2012; WickiStordeur and Swayne, 2013). These cells are normally subject to intense and differing mechanical forces from the time they are born through their journey along the rostral migratory stream under physiologically normal conditions. These forces are elicited through the influence of multiple types of extracellular matrix proteins and various geometrical constraints (reviewed in Barros et al., 2011 and Moore and Sheetz, 2011).

\section{Panx1 DIRECTLY INTERACTS WITH THE ACTIN CYTOSKELETON}

Bhalla-Gehi and colleagues first demonstrated that ectopically expressed Panxl interacts with actin (through the C-terminus of Panx1), and that actin microfilaments are critical for Panxl trafficking to and stability at the plasma membrane (Bhalla-Gehi et al., 2010). Cytochalasin B treatment, an actin filament-destabilizing compound, significantly disrupted the plasma membrane distribution and mobility of Panx1-EGFP in the breast cancer-derived, BICR-M1Rk cell line. In contrast, Panx1-EGFP was insensitive to nocodazole-mediated disruption of microtubules.

Actin and its modulator, actin-related protein 3 (Arp3), were two of several cytoskeletal proteins we recently identified as Panx1-interacting proteins by immunoprecipitation coupled to liquid chromatography and tandem mass spectrometry (LCMS/MS; Wicki-Stordeur and Swayne, 2013). We additionally co-precipitated endogenous Panx1, actin and Arp3, further supporting the idea that these physical interactions occur naturally and are relevant to Panx1 function and signaling. Arp3 closely resembles actin monomers in structure and is part of the seven subunit Arp2/3 actin-modifying complex (reviewed in FiratKaralar and Welch, 2011). In fact, Arp2/3 functions as a nucleation site for new microfilaments, which effectively generates a Y-branched network that allows for actin-mediated mechanical force generation (Mogilner, 2006).

\section{Panx1 IS IMPLICATED IN CELL BEHAVIORS RELIANT ON ACTIN REMODELING}

Using pharmacological tools (probenecid), siRNA-mediated Panx1 knockdown and plasmid-mediated Panxl overexpression, we further determined that Panxl has a major influence on neurite outgrowth and cell migration in Neuro-2a cells and ventricular zone neural stem and progenitor cells (Wicki-Stordeur and Swayne, 2013). We found that Panxl is positively associated with cell migration, whereas it negatively regulates neurite outgrowth. Neurite extension and cell migration are two cellular behaviors that are heavily reliant on complex coordination of both actin and microtubular cytoskeletal dynamics (recently reviewed in Schaefer et al., 2008; Kaverina and Straube, 2011; Salbreux et al., 2012).

An earlier study on C6 glioma cells engineered to express Panx1, demonstrated that ectopic Panxl overtakes control of the actomyosin system to accelerate the compaction of multicellular C6 glioma aggregates (Lai et al., 2007). Furthermore, the authors observed an enhancement of ATP release attributable to Panx1 overexpression, as well as $\mathrm{P} 2 \mathrm{X} 7$ receptor modulator sensitivity to the Panx1-mediated changes in cell compaction implicated in the remodeling. In addition to these predictable observations, the presence of Panx1 also had a significant impact on the distribution of the actin cortical network.

Work by several groups had earlier established a connection between P2X receptors and the actin cytoskeleton (Kim et al., 2001; Pubill et al., 2001; Pfeiffer et al., 2004). Essentially, P2X7 receptors were shown to interact with actin (Kim et al., 2001), while other groups demonstrated that ATP activation of P2X receptors promotes actin network restructuring through an actinmodifying complex to alter cellular morphology (Pubill et al., 2001; Pfeiffer et al., 2004). In our proteomic analysis of Panx1 interacting partners (Wicki-Stordeur and Swayne, 2013) we identified actin, Arp3 and other cytoskeletal regulators, and additional 
proteins, but we did not detect $\mathrm{P} 2 \mathrm{X} 7$ receptors. It is not known whether P2X7 receptors are bystanders, or are requisite for the crosstalk between Panxl and the actin cytoskeleton. Further, whether their involvement is cell-type specific or state-specific (physiological vs. pathophysiological; see Morelli et al., 2003 and Homma et al., 2008) remains to be determined.

\section{OTHER EFFECTS OF Panx1 EXPRESSION ON THE CYTOSKELETON}

Not only is it likely that Panxl functionally interacts with the cytoskeleton, but it can also alter the cytoskeletal proteome, as recently shown by Penuela et al. (2012). This group investigated the role of Panx1 in melanoma tumorigenesis and metastasis, and found that increased Panx1 expression correlated with tumor "aggressiveness." An shRNA-mediated reduction in Panxl expression was able to revert the tumor cells to a more melanocytic phenotype (reduced cell migration, increased melanin production and process formation). Using a $2 \mathrm{D}$ gel/mass spectrometry approach, the authors identified two important cell structure proteins that were down regulated by the reduction in Panx1, vimentin, an intermediate filament protein, and beta-catenin, an important regulator of cell adhesion. Earlier, Lai and colleagues demonstrated that ectopic expression of Panx1 in C6 glioma cells resulted in a dramatically altered cell morphology (Lai et al., 2007). Panx1 expression led to a flattened morphology quite distinct from the spindle-shaped morphology normally exhibited by these cells. The precise cytoskeletal alterations resulting in this striking change in cell shape were not identified.

These studies along with our recent discovery that modulating Panxl expression and function has a dramatic impact on neurite outgrowth in Neuro-2a cells and ventricular zone neural stem and progenitor cells (Wicki-Stordeur and Swayne, 2013) suggest that Panxl is an important cytoskeletal regulator.

\section{CONCLUDING REMARKS}

It is becomingly increasingly clear that the functional role of Panxl in cells is closely tied to the cytoskeleton. Panxl is sensitive to stretch, is involved in cytoskeletal-associated cell behaviors and physically interacts with actin. Further, Panx1 exerts influence on the expression of cytoskeletal proteins and when ectopically expressed, can infiltrate and overtake control of the actin cytoskeleton, even though it is not normally present. This suggests that Panx1 is likely a powerful regulator of the cytoskeleton in cells in which it is endogenously expressed.

We are now working on unraveling the mechanistic details underlying the crosstalk between Panx1, actin, the Arp2/3 complex and the other cytoskeletal elements, including elements associated with microtubular dynamics uncovered by our unbiased proteomic analysis of Panx1 interactors in cells that endogenously express Panx1. By studying these interactions, we hope to gain detailed information on the molecular players that are key to Panx1/cytoskeletal crosstalk. This work will bridge significant knowledge gaps in our understanding of the physiological and pathophysiological roles of Panxl.

\section{AUTHOR CONTRIBUTIONS}

Leigh Anne Swayne conceived of the topic, while Leigh Anne Swayne, Andrew K. J. Boyce, and Leigh E. Wicki-Stordeur co-wrote the body of the manuscript. Andrew K. J. Boyce and Leigh E. Wicki-Stordeur together wrote the abstract. Leigh Anne Swayne, Andrew K. J. Boyce, and Leigh E. Wicki-Stordeur revised the manuscript. All authors approve of the manuscript and its contents.

\section{ACKNOWLEDGMENTS}

Research in the Swayne lab is supported by an NSERC Discovery grant, a Heart and Stroke Foundation Partnership for Stroke Recovery grant and a University of Victoria Division of Medical Sciences startup grant. Andrew K. J. Boyce is supported by an NSERC Canadian Graduate Scholarship-Masters and a University of Victoria Graduate Award. Leigh E. WickiStordeur is supported by a Vanier Canada Graduate Scholarship (NSERC), a Howard E. Petch research scholarship, and an Edythe Hembroff-Schleicher graduate scholarship. We thank the Victoria Foundation Willard and Elva Dawson Fund for previous stipend support for Andrew K. J. Boyce and Leigh E. Wicki-Stordeur. We are grateful to the Canadian Foundation for Innovation and the British Columbia Knowledge Development Fund for granting funds for our confocal microscope.

\section{REFERENCES}

Bao, L., Locovei, S., and Dahl, G. (2004). Pannexin membrane channels are mechanosensitive conduits for ATP. FEBS Lett. 572, 65-68. doi: 10.1016/j.febslet.2004.07.009

Barros, C. S., Franco, S. J., and Muller, U. (2011). Extracellular matrix: functions in the nervous system. Cold Spring Harb. Perspect. Biol. 3:a005108. doi: 10.1101/cshperspect.a005108

Bhalla-Gehi, R., Penuela, S., Churko, J. M., Shao, Q., and Laird, D. W. (2010). Pannexin1 and pannexin3 delivery, cell surface dynamics, and cytoskeletal interactions. J. Biol. Chem. 285, 9147-9160. doi: 10.1074/jbc.M109.082008

Bruzzone, R., Hormuzdi, S. G., Barbe, M. T., Herb, A., and Monyer, H. (2003). Pannexins, a family of gap junction proteins expressed in brain. Proc. Natl. Acad. Sci. U.S.A. 100, 13644-13649. doi: 10.1073/pnas.2233464100

Firat-Karalar, E. N., and Welch, M. D. (2011). New mechanisms and functions of actin nucleation. Curr. Opin. Cell Biol. 23, 4-13. doi: 10.1016/j.ceb.2010.10.007

Hamill, O. P. (2006). Twenty odd years of stretch-sensitive channels. Pflugers Arch. Eur. J. Physiol. 453, 333-351. doi: 10.1007/s00424-006-0131-0

Hayakawa, K., Tatsumi, H., and Sokabe, M. (2008). Actin stress fibers transmit and focus force to activate mechanosensitive channels. J. Cell Sci. 121, 496-503. doi: $10.1242 /$ jcs.022053

Homma, K., Niino, Y., Hotta, K., and Oka, K. (2008). Ca(2+) influx through $\mathrm{P} 2 \mathrm{X}$ receptors induces actin cytoskeleton reorganization by the formation of cofilin rods in neurites. Mol. Cell. Neurosci. 37, 261-270. doi: 10.1016/j.mcn.2007.10.001

Horber, J. K., Mosbacher, J., Haberle, W., Ruppersberg, J. P., and Sakmann, B. (1995). A look at membrane patches with a scanning force microscope. Biophys. J. 68, 1687-1693. doi: 10.1016/S0006-3495(95)80346-2

Jaqaman, K., and Grinstein, S. (2012). Regulation from within: the cytoskeleton in transmembrane signaling. Trends Cell Biol. 22, 515-526. doi: 10.1016/j.tcb.2012.07.006

Kaverina, I., and Straube, A. (2011). Regulation of cell migration by dynamic microtubules. Semin. Cell Dev. Biol. 22, 968-974. doi: 10.1016/j.semcdb.2011. 09.017

Kim, M., Jiang, L. H., Wilson, H. L., North, R. A., and Surprenant, A. (2001). Proteomic and functional evidence for a $\mathrm{P} 2 \mathrm{X} 7$ receptor signalling complex. EMBO J. 20, 6347-6358. doi: 10.1093/emboj/20.22.6347

Lai, C. P., Bechberger, J. F., Thompson, R. J., MacVicar, B. A., Bruzzone, R., and Naus, C. C. (2007). Tumor-suppressive effects of pannexin 1 in C6 glioma cells. Cancer Res. 67, 1545-1554. doi: 10.1158/0008-5472.CAN06-1396

Laplaca, M. C., and Prado, G. R. (2010). Neural mechanobiology and neuronal vulnerability to traumatic loading. J. Biomech. 43, 71-78. doi: 10.1016/j.jbiomech.2009.09.011 
Lim, C. T., Bershadsky, A., and Sheetz, M. P. (2010). Mechanobiology. J. R. Soc. Interface 7(Suppl. 3), S291-S293. doi: 10.1098/rsif.2010.0150.focus

Locovei, S., Bao, L., and Dahl, G. (2006). Pannexin 1 in erythrocytes: function without a gap. Proc. Natl. Acad. Sci. U.S.A. 103, 7655-7659. doi: 10.1073/pnas.0601037103

Mogilner, A. (2006). On the edge: modeling protrusion. Curr. Opin. Cell Biol. 18, 32-39. doi: 10.1016/j.ceb.2005.11.001

Moore, S. W., and Sheetz, M. P. (2011). Biophysics of substrate interaction: influence on neural motility, differentiation, and repair. Dev. Neurobiol. 71, 1090-1101. doi: 10.1002/dneu.20947

Morelli, A., Chiozzi, P., Chiesa, A., Ferrari, D., Sanz, J. M., Falzoni, S., et al. (2003). Extracellular ATP causes ROCK I-dependent bleb formation in P2X7transfected HEK293 cells. Mol. Biol. Cell 14, 2655-2664. doi: 10.1091/mbc.0204-0061

Panchin, Y., Kelmanson, I., Matz, M., Lukyanov, K., Usman, N., and Lukyanov, S. (2000). A ubiquitous family of putative gap junction molecules. Curr. Biol. 10, R473-R474. doi: 10.1016/S0960-9822(00)00576-5

Penuela, S., Gyenis, L., Ablack, A., Churko, J. M., Berger, A. C., Litchfield, D. W., et al. (2012). Loss of pannexin 1 attenuates melanoma progression by reversion to a melanocytic phenotype. J. Biol. Chem. 287, 29184-29193. doi: 10.1074/jbc.M112.377176

Pfeiffer, Z. A., Aga, M., Prabhu, U., Watters, J. J., Hall, D. J., and Bertics, P. J. (2004). The nucleotide receptor P2X7 mediates actin reorganization and membrane blebbing in RAW 264.7 macrophages via p38 MAP kinase and Rho. J. Leukoc. Biol. 75, 1173-1182. doi: 10.1189/jlb.1203648

Pubill, D., Dayanithi, G., Siatka, C., Andres, M., Dufour, M. N., Guillon, G., et al. (2001). ATP induces intracellular calcium increases and actin cytoskeleton disaggregation via P2x receptors. Cell Calcium 29, 299-309. doi: 10.1054/ceca.2000.0194

Richter, K., Kiefer, K. P., Grzesik, B. A., Clauss, W. G., and Fronius, M. (2014). Hydrostatic pressure activates ATP-sensitive $\mathrm{K}+$ channels in lung epithelium by ATP release through pannexin and connexin hemichannels. FASEB J. 28, 45-55. doi: 10.1096/fj.13-229252

Salbreux, G., Charras, G., and Paluch, E. (2012). Actin cortex mechanics and cellular morphogenesis. Trends Cell Biol. 22, 536-545. doi: 10.1016/j.tcb.2012.07.001

Schaefer, A. W., Schoonderwoert, V. T., Ji, L., Mederios, N., Danuser, G., and Forscher, P. (2008). Coordination of actin filament and microtubule dynamics during neurite outgrowth. Dev. Cell 15, 146-162. doi: 10.1016/j.devcel.2008.05.003

Seminario-Vidal, L., Okada, S. F., Sesma, J. I., Kreda, S. M., van Heusden, C. A., Zhu, Y., et al. (2011). Rho signaling regulates pannexin 1-mediated ATP release from airway epithelia. J. Biol. Chem. 286, 26277-26286. doi: 10.1074/jbc.M111.260562

Wicki-Stordeur, L. E., Dzugalo, A. D., Swansburg, R. M., Suits, J. M., and Swayne, L. A. (2012). Pannexin 1 regulates postnatal neural stem and progenitor cell proliferation. Neural Dev. 7, 11. doi: 10.1186/17498104-7-11

Wicki-Stordeur, L. E., and Swayne, L. A. (2013). Panx1 regulates neural stem and progenitor cell behaviours associated with cytoskeletal dynamics and interacts with multiple cytoskeletal elements. Cell Commun. Signal. 11, 62. doi: 10.1186/1478-811X-11-62

Xia, J., Lim, J. C., Lu, W., Beckel, J. M., Macarak, E. J., Laties, A. M., et al. (2012). Neurons respond directly to mechanical deformation with pannexin-mediated ATP release and autostimulation of P2X7 receptors. J. Physiol. 590, 2285-2304. doi: 10.1113/jphysiol.2012.227983

Conflict of Interest Statement: The authors declare that the research was conducted in the absence of any commercial or financial relationships that could be construed as a potential conflict of interest.

Received: 01 November 2013; accepted: 13 January 2014; published online: 30 January 2014.

Citation: Boyce AKJ, Wicki-Stordeur LE and Swayne LA (2014) Powerful partnership: crosstalk between pannexin 1 and the cytoskeleton. Front. Physiol. 5:27. doi: 10.3389/ fphys.2014.00027

This article was submitted to Membrane Physiology and Membrane Biophysics, a section of the journal Frontiers in Physiology.

Copyright (๑) 2014 Boyce, Wicki-Stordeur and Swayne. This is an open-access article distributed under the terms of the Creative Commons Attribution License (CC BY). The use, distribution or reproduction in other forums is permitted, provided the original author(s) or licensor are credited and that the original publication in this journal is cited, in accordance with accepted academic practice. No use, distribution or reproduction is permitted which does not comply with these terms. 